\title{
Changes and open issues in the management of differentiated thyroid carcinoma: an overview
}

\author{
Markus Luster $\cdot$ Theresia Weber $\cdot$ Frederik A. Verburg
}

Received: 22 March 2013/Accepted: 11 May 2013/Published online: 29 May 2013

(C) Italian Association of Nuclear Medicine and Molecular Imaging 2013

\begin{abstract}
Many of the topics briefly addressed in this article are discussed more extensively in this issue of Clinical and Translational Molecular Imaging by distinguished colleagues from all fields related to the care of differentiated thyroid cancer (DTC) patients. Several open issues in the management of DTC are fueled by the progress that has been made in the past decade, which is an indication of the liveliness of this scientific field. Aside from some remarkable results achieved in basic and clinical research, the greatest improvements and achievements in this field in recent years concern truly multidisciplinary research and patient-oriented guidelines. These should pave the way for future initiatives to build on the advances achieved in DTC care in the recent past.
\end{abstract}

Keywords Thyroid cancer - Radioiodine - Cancer management $\cdot$ Treatment $\cdot$ Follow-up

The incidence of differentiated thyroid cancer (DTC) has increased considerably over recent decades, a trend considered to be driven mainly by improved diagnosis (linked to the more frequent use and methodological improvements of neck ultrasound) [1]. Nowadays, smaller malignant

\footnotetext{
M. Luster ( $\square)$

Department of Nuclear Medicine, Ulm University Hospital, Albert-Einstein-Allee 23, 89081 Ulm, Germany

e-mail: Markus.luster@uniklinik-ulm.de

T. Weber

Department of Surgery, Ulm University Hospital, Ulm, Germany

F. A. Verburg

Department of Nuclear Medicine, Aachen University Hospital,

Aachen, Germany
}

lesions, representing earlier stages of differentiated papillary type (PTC) and - to a considerably lesser extentfollicular type (FTC) cancers, make up a much larger proportion of the total number of newly diagnosed DTC cases than they did in the past. These tumors frequently affect younger (under the age of 45), predominantly female, patients who, if treated adequately, mostly have a normal life expectancy [2, 3].

As a consequence, the great challenge today is to prevent "overdiagnosis" and potential "overtreatment" in a bid to reduce the risk of potential side effects of therapy, yet without overlooking more aggressive variants of the disease which require a more intensive follow-up and often need multidisciplinary management.

Globally, the age-standardized incidence rate of thyroid cancer is approximately 16 patients per 100,000 individuals in the general population. In contrast, the age-standardized mortality from thyroid cancer is $<2$ patients per 100,000 individuals.

Thus, the prognosis of DTC is excellent, with 10-year overall survival rates exceeding $90 \%$ after up-to-date treatment (expert surgery often followed by adjuvant ${ }^{131} \mathrm{I}$ ablation). Even though relapse is a relatively rare occurrence after adequate treatment [4], it is certainly not unheard of and the fear of relapsing may have both medical implications and a considerable impact on patients' quality of life, in the sense that this fear will stop many patients from achieving the peace of mind they long for [5].

Questions regarding the appropriate surgical approach to adopt-lobectomy versus thyroidectomy and whether or not to perform central lymph node dissection-continue to be intensely debated in the literature [6]. The goal of prophylactic central neck dissection is to improve longterm regional disease control and/or survival. Whether the procedure achieves this goal is an unresolved issue on 
which thyroid surgeons are divided, as shown by the inconsistent recommendations in the published national and international guidelines [6, 7]. There does, however, appear to be a general consensus that modified radical neck dissection of the lateral compartment should be reserved for patients with known lymph node (LN) metastases.

Locoregionally metastasizing disease of variable extension is frequent, especially in patients with PTCs. Reported incidences range from $35 \%$ to more than $70 \%$ in different series and regional recurrence is comparatively common. Patient's age and the presence of grossly enlarged lateral cervical nodes appear to be determining factors for the risk of recurrence in this patient group. Detection of LN involvement may depend, among other contributing factors, on the extent of LN surgery, but it is also related to the size of the primary tumor $[8,9]$.

It has been shown that diagnostic or post-therapeutic ${ }^{131} \mathrm{I}$ SPECT/CT of the neck has a complementary value to planar imaging in the scanning of DTC patients [10].

As general recommendations, more "aggressive" procedures should be performed by "experienced hands" and potential complications of cervical LN dissection, e.g., temporary/permanent hypoparathyroidism and/or recurrent inferior laryngeal nerve injury, must be weighed up against the possible benefits.

Pre-therapeutic imaging after the application of a diagnostic activity of ${ }^{131}$ I (i.e., exceeding $10-20 \mathrm{MBq}$ ) before radioiodine treatment may result in a reduced uptake of the subsequent therapeutic activity, a phenomenon that is also referred to as "stunning" $[11,12]$. Therefore, the use of ${ }^{123} \mathrm{I}$ or the PET tracer ${ }^{124} \mathrm{I}$ should be preferred if pre-therapeutic scanning for assessment of iodine avidity and the extent of disease is required.

Since the first application of radioiodine for the treatment of differentiated thyroid cancer, post-surgical thyroid ablation has become a standard of care in most centers. The rationale for thyroid remnant ablation is mainly to eradicate microfoci of cancer tissue which might be a reservoir for future recurrences. However, after 70 years of practice, physicians have still not reached a consensus on the indications, the amount of radioiodine to be administered, or the method of preparation for ablation. The indications for radioiodine ablation have been reassessed in current guidelines and a general notion has evolved that candidates for adjuvant therapy should be selected on the basis of their individual risk of recurrence $[6,13,14]$.

It is commonly accepted that patients at high risk of recurrence or thyroid cancer-related death will benefit from radioiodine treatment; whereas so-called low-risk patients (i.e., with tumors $\leq 1 \mathrm{~cm}$ and without lymphatic or distant metastatic spread) should definitely be spared this modality. Instead, the value of radioiodine treatment in patients falling in between these two groups (i.e., in those at intermediate risk) has not been unequivocally established; however, many of these patients may benefit from radioiodine therapy, whereas others would probably do (equally) well without adjuvant therapy after surgery. In 2008, Sawka et al. [15] demonstrated in their meta-analysis that ${ }^{131}$ I remnant ablation is significantly important in avoiding recurrence and later metastatic disease.

The quantity of ${ }^{131}$ I to use is another open issue. Until recently, fixed activities of $3.7 \mathrm{GBq}$ or more were routinely administered, but there is growing evidence that lower amounts of the radioactive compound can, alternatively, be used in certain subgroups; this suggestion is based on the finding that short-term results of radioiodine therapy with lower activities appear to be equivalent to those obtained using higher activities [16, 17].

Similarly, the concept that thyroid ablation should be performed after thyroid hormone withdrawal (THW) has been questioned in favor of the use of exogenous stimulation with recombinant human TSH (rhTSH), which in several studies has been found to be equivalent to THW both when using high and low radioiodine activities [16-19].

In radioiodine therapy for persistent or metastatic disease, the activity actually administered is chosen on the basis of a physician or institution's estimation of the amount of radioiodine needed to deliver the highest safe radiation dose (to neoplastic foci), taking into account the patient's tumor burden, amount of remnant tissue, age, etc.

Chiesa et al. [20] described important changes in tumor/ lesion biokinetics in patients undergoing multiple courses of treatment for persistent disease accompanied by a loss of therapeutic efficacy along the sequence of fixed activity administrations.

The rationale underlying individual dosimetry is to calculate the amount of ${ }^{131} \mathrm{I}$ to use and the resulting absorbed dose to iodine-avid thyroid tissue, which must be maximized for each patient while avoiding bone marrow toxicity, pulmonary fibrosis, and other potential side effects [21]. An alternative approach for treating the advanced stages of DTC is to establish and use the activity that is as high as safely administrable (AHASA), i.e., that delivers an absorbed dose of $2 \mathrm{~Gy}$ to the organ at risk, i.e., the bone marrow; in practice, the blood dose is used as a surrogate parameter [22].

Finally, the most frequent permanent side effect of (repeated) radioiodine therapy is xerostomia due to chronic sialadenitis, sometimes leading to a loss of taste and an increased risk of caries. The value of salivary gland stimulation, using lemon juice or sour drops for example, remains unclear, as does the optimal timing of such "interventions" [23, 24].

The definition of "iodine refractory thyroid cancers" is becoming increasingly relevant since the recent advent of new therapeutic agents for patients suffering from 
advanced PTC or FTC, or poorly differentiated cancers that are unresponsive to radioiodine treatment [25]. The estimated incidence of local recurrent or metastatic DTC is 4,000 patients per year in Europe, and it usually carries a poor prognosis. No conventional chemotherapies have shown long-term success, prompting an intensive search for novel options for this demanding subgroup of patients. A minority of patients with a mixed response to ${ }^{131} \mathrm{I}$, who may have developed resistant clones over time, also require a different therapeutic intervention. The loss of sodium/ iodide symporter (NIS) expression (an essential biological function) is correlated with tumor aggressiveness and often mirrored by increased glucose consumption, as demonstrated in FDG PET/CT scanning [26, 27].

Redifferentiating agents have been tested in multiple trials, but none of these compounds has entered clinical routine [28], although the novel agent selumetinib was recently shown to re-induce therapeutically meaningful ${ }^{131} \mathrm{I}$ uptake in $40 \%(8 / 20)$ of patients [29]. Most of the new drugs being developed for the treatment of ${ }^{131}$ I-refractory DTC are agents targeted to molecular pathways thought to be critical for tumor growth [30]. In nearly all cases of PTC, genetic defects involving the RET, RAS, and RAF protein kinase signaling cascade are identified; however, the genetic mechanisms underlying FTC are less clear [31].

Questions related to patient selection, patient-relevant endpoints, and the potential duration of treatment with these many new therapeutic compounds are still open and should be the prime considerations in designing new trials.

Many of the topics briefly addressed above are discussed more extensively in this issue of Clinical and Translational Molecular Imaging by distinguished colleagues from all fields related to the care of DTC patients. Several open issues in the management of DTC are fueled by the progress that has been made in the past decade, which is an indication of the liveliness of this scientific field. Aside from some remarkable results achieved in basic and clinical research, the greatest improvements and achievements in this field in recent years concern truly multidisciplinary research and patient-oriented guidelines. These should pave the way for future initiatives to build on the advances achieved in DTC care in the recent past.

Conflict of interest Markus Luster has had research grant support from Bayer Inc., Genzyme Inc., has accepted speakers' fees from Sanofi Inc., Genzyme Inc., and is a consultant to Genzyme and a member of its speaker bureau. Theresia Weber has had research grant support from the Braun Stiftung and has accepted speakers' fees from Genzyme Inc. Frederik A. Verburg has had research grant support from Genzyme Inc. and has accepted speakers' fees from Genzyme Inc.

Human and Animal Studies This article does not contain any studies with human or animal subjects performed by the any of the authors.

\section{References}

1. Chen AY, Jemal A, Ward EM (2009) Increasing incidence of differentiated thyroid cancer in the United States, 1988-2005. Cancer 115:3801-3807

2. Reiners C, Hanscheid H, Luster M, Lassmann M, Verburg FA (2011) Radioiodine for remnant ablation and therapy of metastatic disease. Nat Rev Endocrinol. doi:10.1038/nrendo.2011.134

3. Verburg FA, Mader U, Tanase K, Thies ED, Diessl S, Buck AK, Luster M, Reiners C (2013) Life expectancy is reduced in differentiated thyroid cancer patients $\geq 45$ years old with extensive local tumor invasion, lateral lymph node, or distant metastases at diagnosis and normal in all other DTC patients. J Clin Endocrinol Metab 98:172-180

4. Verburg FA, Stokkel MP, Duren C, Verkooijen RB, Mader U, van Isselt JW, Marlowe RJ, Smit JW, Reiners C, Luster M (2010) No survival difference after successful (131)I ablation between patients with initially low-risk and high-risk differentiated thyroid cancer. Eur J Nucl Med Mol Imaging 37:276-283

5. Hoftijzer HC, Heemstra KA, Corssmit EP, van der Klaauw AA, Romijn JA, Smit JW (2008) Quality of life in cured patients with differentiated thyroid carcinoma. J Clin Endocrinol Metab 93:200-203

6. Cooper DS, Doherty GM, Haugen BR, Kloos RT, Lee SL, Mandel SJ, Mazzaferri EL, McIver B, Pacini F, Schlumberger M, Sherman SI, Steward DL, Tuttle RM (2009) Revised American Thyroid Association management guidelines for patients with thyroid nodules and differentiated thyroid cancer. Thyroid 19:1167-1214

7. Musholt TJ, Clerici T, Dralle H, Frilling A, Goretzki PE, Hermann MM, Kussmann J, Lorenz K, Nies C, Schabram J, Schabram P, Scheuba C, Simon D, Steinmuller T, Trupka AW, Wahl RA, Zielke A, Bockisch A, Karges W, Luster M, Schmid KW (2011) German Association of Endocrine Surgeons practice guidelines for the surgical treatment of benign thyroid disease. Langenbecks Arch Surg 396:639-649

8. Machens A, Holzhusen HJ, Dralle H (2005) The prognostic value of primary tumor size in papillary and follicular thyroid carcinoma. A comparative analysis. Cancer 103:2269-2273

9. Verburg FA, Mader U, Luster M, Reiners C (2009) Primary tumour diameter as a risk factor for advanced disease features of differentiated thyroid carcinoma. Clin Endocrinol (Oxf) 71:291-297

10. Schmidt D, Szikszai A, Linke R, Bautz W, Kuwert T (2009) Impact of 131I SPECT/spiral CT on nodal staging of differentiated thyroid carcinoma at first radioablation. J Nucl Med 50:18-23

11. Lassmann M, Luster M, Hanscheid H, Reiners C (2004) Impact of 131I diagnostic activities on the biokinetics of thyroid remnants. J Nucl Med 45:619-625

12. Verburg FA, Verkooijen R, Stokkel M, van Isselt J (2009) The success of 131I ablation in thyroid cancer patients is significantly reduced after a diagnostic activity of $40 \mathrm{MBq}$ 131I. Nuklearmedizin 48:138-142

13. Pacini F, Schlumberger M, Dralle H, Elisei R, Smit JW, Wiersinga W (2006) European consensus for the management of patients with differentiated thyroid carcinoma of the follicular epithelium. Eur J Endocrinol 154:787-803

14. Luster M, Clarke SE, Dietlein M, Lassmann M, Lind P, Oyen WJ, Tennvall J, Bombardieri E (2008) Guidelines for radioiodine therapy of differentiated thyroid cancer. Eur J Nucl Med Mol Imaging 35:1941-1959

15. Sawka AM, Brierley JD, Tsang RW, Thabane L, Rotstein L, Gafni A, Straus S, Goldstein DP (2008) An updated systematic review and commentary examining the effectiveness of 
radioactive iodine remnant ablation in well-differentiated thyroid cancer. Endocrinol Metab Clin North Am 37:457-480

16. Schlumberger M, Catargi B, Borget I, Deandreis D, Zerdoud S, Bridji B, Bardet S, Leenhardt L, Bastie D, Schvartz C, Vera P, Morel O, Benisvy D, Bournaud C, Bonichon F, Dejax C, Toubert ME, Leboulleux S, Ricard M, Benhamou E (2012) Strategies of radioiodine ablation in patients with low-risk thyroid cancer. N Engl J Med 366:1663-1673

17. Mallick U, Harmer C, Yap B, Wadsley J, Clarke S, Moss L, Nicol A, Clark PM, Farnell K, McCready R, Smellie J, Franklyn JA, John R, Nutting CM, Newbold K, Lemon C, Gerrard G, AbdelHamid A, Hardman J, Macias E, Roques T, Whitaker S, Vijayan R, Alvarez P, Beare S, Forsyth S, Kadalayil L, Hackshaw A (2012) Ablation with low-dose radioiodine and thyrotropin alfa in thyroid cancer. N Engl J Med 366:1674-1685

18. Tuttle RM, Brokhin M, Omry G, Martorella AJ, Larson SM, Grewal RK, Fleisher M, Robbins RJ (2008) Recombinant human TSH-assisted radioactive iodine remnant ablation achieves shortterm clinical recurrence rates similar to those of traditional thyroid hormone withdrawal. J Nucl Med 49:764-770

19. Pacini F, Ladenson PW, Schlumberger M, Driedger A, Luster M, Kloos RT, Sherman S, Haugen B, Corone C, Molinaro E, Elisei R, Ceccarelli C, Pinchera A, Wahl RL, Leboulleux S, Ricard M, Yoo J, Busaidy NL, Delpassand E, Hanscheid H, Felbinger R, Lassmann M, Reiners C (2006) Radioiodine ablation of thyroid remnants after preparation with recombinant human thyrotropin in differentiated thyroid carcinoma: results of an international, randomized, controlled study. J Clin Endocrinol Metab 91:926-932

20. Chiesa C, Castellani MR, Vellani C, Orunesu E, Negri A, Azzeroni R, Botta F, Maccauro M, Aliberti G, Seregni E, Lassmann M, Bombardieri E (2009) Individualized dosimetry in the management of metastatic differentiated thyroid cancer. Q J Nucl Med Mol Imaging 53:546-561

21. Lassmann M, Reiners C, Luster M (2010) Dosimetry and thyroid cancer: the individual dosage of radioiodine. Endocr Relat Cancer 17:R161-R172

22. Lassmann M, Haenscheid H, Chiesa C, Hindorf C, Flux G, Luster M (2008) EANM Dosimetry Committee series on standard operational procedures for pre-therapeutic dosimetry I: blood and bone marrow dosimetry in differentiated thyroid cancer therapy. Eur J Nucl Med Mol Imaging 35:1405-1412
23. Jentzen W, Schmitz J, Freudenberg L, Eising E, Hilbel T, Bockisch A, Stahl A (2010) The influence of saliva flow stimulation on the absorbed radiation dose to the salivary glands during radioiodine therapy of thyroid cancer using 124I PET(/CT) imaging. Eur J Nucl Med Mol Imaging 37:2298-2306

24. Nakada K, Ishibashi T, Takei T, Hirata K, Shinohara K, Katoh S, Zhao S, Tamaki N, Noguchi Y, Noguchi S (2005) Does lemon candy decrease salivary gland damage after radioiodine therapy for thyroid cancer? J Nucl Med 46:261-266

25. Cabanillas ME, Waguespack SG, Bronstein Y, Williams MD, Feng L, Hernandez M, Lopez A, Sherman SI, Busaidy NL (2010) Treatment with tyrosine kinase inhibitors for patients with differentiated thyroid cancer: the M. D Anderson experience. J Clin Endocrinol Metab 95:2588-2595

26. Wang W, Larson SM, Fazzari M, Tickoo SK, Kolbert K, Sgouros G, Yeung H, Macapinlac H, Rosai J, Robbins RJ (2000) Prognostic value of $[18 \mathrm{~F}]$ fluorodeoxyglucose positron emission tomographic scanning in patients with thyroid cancer. J Clin Endocrinol Metab 85:1107-1113

27. Alzahrani AS, Abouzied ME, Salam SA, Mohamed G, Rifai A, Al Sugair A, Amin T (2008) The role of F-18-fluorodeoxyglucose positron emission tomography in the postoperative evaluation of differentiated thyroid cancer. Eur J Endocrinol 158:683-689

28. Short SC, Suovuori A, Cook G, Vivian G, Harmer C (2004) A phase II study using retinoids as redifferentiation agents to increase iodine uptake in metastatic thyroid cancer. Clin Oncol ( R Coll Radiol) 16:569-574

29. Ho AL, Grewal RK, Leboeuf R, Sherman EJ, Pfister DG, Deandreis D, Pentlow KS, Zanzonico PB, Haque S, Gavane S, Ghossein RA, Ricarte-Filho JC, Dominguez JM, Shen R, Tuttle RM, Larson SM, Fagin JA (2013) Selumetinib-enhanced radioiodine uptake in advanced thyroid cancer. $\mathrm{N}$ Engl $\mathrm{J}$ Med 368:623-632

30. Pacini F, Ito Y, Luster M, Pitoia F, Robinson B, Wirth L (2012) Radioactive iodine-refractory differentiated thyroid cancer: unmet needs and future directions. Expert Rev Endocrinol Metab 7:541-554

31. Handkiewicz-Junak D, Czarniecka A, Jarzab B (2010) Molecular prognostic markers in papillary and follicular thyroid cancer: current status and future directions. Mol Cell Endocrinol $322: 8-28$ 